\title{
Patellar and quadriceps tendon abnormalities in obese patients with knee osteoarthritis: a preliminary ultrasonographic study
}

\author{
Maria Grazia Benedetti ${ }^{1}$ \\ Antonio Frizziero ${ }^{2}$ \\ Domenico Affinito ${ }^{3}$ \\ Lorenzo Cavazzuti ${ }^{1}$ \\ Silvia Bonfiglioli Stagni ${ }^{1}$ \\ Stefano Galletti ${ }^{3}$ \\ Fabio Catani ${ }^{4}$ \\ Nicola Maffulli ${ }^{5}$ \\ 1 Physical Medicine and Rehabilitation Unit, Istituto \\ Ortopedico Rizzoli, Bologna, Italy \\ 2 Department of Physical and Rehabilitation Medicine, \\ University of Padua, Italy \\ 3 Diagnostic and Interventional Radiology, Rizzoli \\ Orthopaedic Institute, Bologna, Italy \\ 4 Department of Medical and Surgical Sciences for \\ Children \& Adults, University-Hospital of Modena and \\ Reggio Emilia, Modena, Italy \\ 5 Department of Musculoskeletal Surgery, Azienda \\ Ospedaliera San Giovanni di Dio e Ruggi d'Aragona, \\ University of Salerno, Italy; Queen Mary University of \\ London, Barts and the London School of Medicine \\ and Dentistry, Centre for Sports and Exercise \\ Medicine, Mile End Hospital, London, UK
}

Corresponding author:

Antonio Frizziero

Department of Physical and Rehabilitation Medicine University of Padua

Via Giustiniani 2

35128 Padua, Italy

E-mail: antonio.frizziero@unipd.it

\section{Summary}

Introduction: Obesity is a risk factor for knee osteoarthritis (OA). We hypothesised that, because of mechanical overload and metabolic impairment, obese patients with knee OA present more frequent knee extensor system abnormalities compared to lean osteoarthritis patients at high resolution ultrasonography.

Methods: Twelve obese patients (Obese group) and a control group of ten lean patients (Lean group) with knee OA were included in this study. Short anteroposterior weight-bearing knee radiographs were taken. Femorotibial alignment and Kellgren-
Lawrence score were assessed. Ultrasonographic assessment was performed on the quadriceps and patellar tendons through three scans in both transverse and longitudinal planes, and power-Doppler images were taken.

Results: The Obese group presented a trend toward a higher percentage of low degree radiographic knee OA compared to the Lean group. Ultrasonography evidenced the involvement of the peripatellar entheses, synovitis and effusion at the supra-patellar recess and muscular tissue fibroadipous degeneration, and hypotrophy of rectus femoris, particularly evident in the obese group.

Conclusions: There are marked abnormalities of the quadriceps and patellar tendons both in obese and lean patients with knee OA. Although obese patients were significantly younger than lean patients, the presence of quadriceps and patellar tendons abnormalities in the knee OA Obese group supports the hypothesis of an early onset of abnormal tendon structure in the younger obese population with knee osteoarthritis.

Level of evidence: III.

KEY WORDS: osteoarthritis, knee, ultrasound, patellar tendon, obesity.

\section{Introduction}

Obesity is a risk factor in the pathogenesis of knee osteoarthritis $(O A)^{1-3}$ through an increased mechanical burden leading to altered motion and abnormal loading patterns at the knee ${ }^{4}$. Obesity is associated with lower quadriceps strength per body mass ${ }^{5}$. Since the quadriceps muscle plays an important role in stabilizing the knee, a relative quadriceps weakness in relation to the excess of body weight could determine an increased risk of knee OA in obese people ${ }^{6}$, inducing a higher impact on the cartilage during gait ${ }^{7}$. There is good evidence on the role of thigh muscle weakness in knee osteoarthritis patients ${ }^{8}$.

The relationship between quadriceps strength and knee OA has not been completely elucidated ${ }^{5-6}$, and there has been recently a growing interest on the role of intramuscular fat, which may negatively affect muscle morphology and function ${ }^{9-10}$. Obese subjects present sarcopenia with higher fat infiltration of the quadriceps compared to lean people, which could account for the lower strength production ${ }^{5,9}$. Greater 
quadriceps fat content is associated to mobility limitations, lower quadriceps extensor strength, disability and symptoms ${ }^{9,10}$. Muscle architecture (pennation, muscle fascicle length) in obese people is related to a reduced peak torque at the knee level ${ }^{5,11}$. The presence of intramuscular fat in obese subjects could also be related to the evidence that metabolic dysregulation, through an adipose tissue-associated inflammation process, could also play a role in knee $\mathrm{OA}^{12}$.

Recently, some interest has been devoted to the relationships between obesity, metabolic diseases and tendinopathies ${ }^{13-17}$. There is some evidence that obesity is a risk factor also for tendinopathy at different districts in community based adults, including the patellar tendon ${ }^{15}$. Although tendinopathy has been hypothesized to arise from the reduced ability of the tendon of obese subjects to resist to stress and to repair damages caused by high stress ${ }^{15}$, prolonged systemic low grade inflammation, such as in metabolic insulin dysregulation, has also been called into cause ${ }^{16}$. Spontaneous rupture of the quadriceps tendon in obese patients have been reported ${ }^{16,18}$. Moreover, histopathological changes at the synovio-entheseal complex at the tendon attachment sites have been suggested as a novel mechanism for synovitis in $\mathrm{OA}^{14}$.

The present study analysed the morphological alterations that occur in the quadriceps and patellar tendons of obese patients with knee OA compared to a group of lean OA patients using ultrasonography. We hypothesised that, because of mechanical and metabolical issues, obese patients with knee OA exhibit greater and more frequent knee extensor system abnormalities compared to lean patients with the same pathology.

\section{Materials and methods}

Twelve consecutive obese patients, nine females and three males (obese group), referred to our Rehabilitation Unit, aged between 35 and 70 years, and BMI $>30 \mathrm{~kg} / \mathrm{m}^{2}$, and were included in this pilot study.

A control group of ten lean patients with knee OA (lean group), eight females, two males, consecutively recruited among a population of patients undergoing for total knee arthroplasty, aged between 35 and 70 years, and $\mathrm{BMI}<30 \mathrm{~kg} / \mathrm{m}^{2}$, was included for comparison.

The main inclusion criteria were men or women over 18 years of age with primary unilateral knee OA according to the American College of Rheumatology ${ }^{19}$; first knee OA symptoms detected at least 6 months before study entry; radiographic evidence of knee femoro-tibial OA for the knee under exam defined by the Kellgren and Lawrence grade 1-4; pain and functional limitation during physical activities.

Patients were excluded if they reported previous injury/surgery at the knee, neurological or rheumatic diseases, and diabetes. The side not to be operated was considered for the study in the Lean group (10 knees), while both knees were considered for the
Obese group (24 knees).

The Ethics Committee of our Institution approved the study protocol, and a written informed consent was obtained from all patients participating to the study.

\section{Radiographic and ultrasonographic assessment}

Bilateral short anteroposterior knee weight-bearing radiographs were taken in all patients in the Obese group, while in the Lean group radiographs were taken only of the knee not to be operated.

The anatomical axis was measured as the angle between the lines from the centre of the tibial spines and the centre of femoral shaft and of the tibial shaft. An angle range between $182^{\circ}$ and $184^{\circ}$ was considered normal, $>184^{\circ}$ was defined as valgus, and $<182^{\circ}$ was defined as varus ${ }^{20}$.

Ultrasonographic assessment was performed using a Siemens ANTARES ultrasonography apparatus with a multifrequency probe ranging from 5 to $10 \mathrm{MHz}$ (deep layers) and 10 to $13 \mathrm{MHz}$ (superficial layers). All patients were tested while supine with the knee at flexion of 45 degrees and fully extended.

The quadriceps muscle and the quadriceps and patellar tendons were imaged through three scans in both transverse and longitudinal planes, and with power Doppler images (Fig. 1).

The thickness of the patellar tendon was measured at the proximal $1 / 3$ portion of the tendon before the patellar insertion, both in longitudinal and sagittal scans. The course of the patellar tendon was classified as normal or lateralized. All measurements were performed using the recommendations from the European Society of Musculoskeletal Radiology21. Muscle tissue fibroadipous degeneration of the quadriceps was considered as $0=a b s e n t, 1=$ present. The muscle bulk of the rectus femoris was scored as $0=$ normal, $1=$ slight hypotrophy, 2 =hypotrophy 22 .

Infrapatellar bursitis was graded as $0=$ absent, $1=$ enlarged $>2 \mathrm{~mm}$ in both scans. Effusion at the suprapatellar recess was considered in the presence of hypoechoic or anechoic intra-articular material with the knee extended and during at 45 degrees of flexion. The presence of increased blood flow of the patellar and quadriceps tendons was also assessed in both longitudinal and sagittal scan at 15 degree of knee flexion, and scored as absent (0) or present (1) at Power Doppler imaging according to the OMERACT criteria $^{23}$. Measurements obtained in the two groups (obese vs lean patients) were compared by means of Mann Whitney test. Categorical variables were summarized in terms of frequency and contingency tables with Kendall-tau b test was used to assess difference. All the statistical analyses were performed using SPSS 11.0 (SPSS, Chicago, Illinois, USA).

\section{Results}

Obese patients were significantly younger compared to the lean ones (52 vs $64.1 \mathrm{yrs}$ ), and they exhibited greater patellar tendon thickness $(4 \mathrm{~mm}$ vs $2.8 \mathrm{~mm}$, 


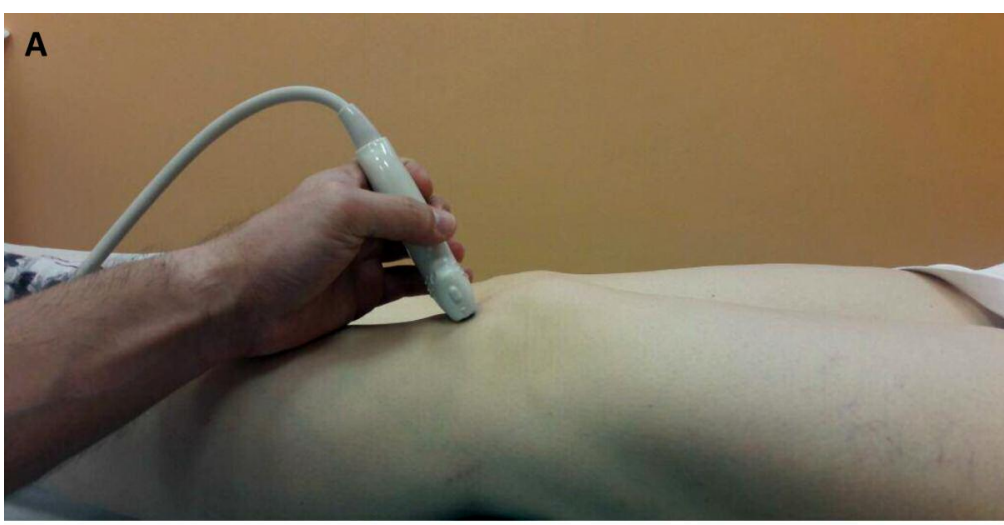

Figure 1. The quadriceps muscle and the quadriceps and Probe positioning to visualize patellar tendon in transverse plane $(A)$ and quadriceps in longitudinal plane (B).

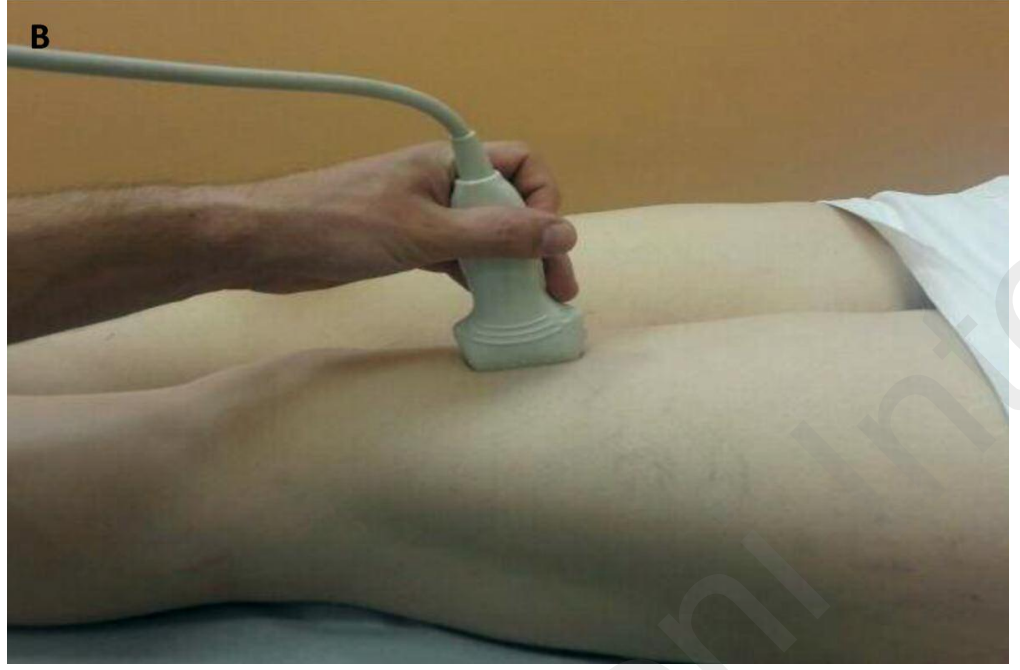

$\mathrm{p}=0.001)($ Tab. I). The Obese group presented a trend toward a higher percentage of subjects with a low degree of radiographic knee OA compared to the Lean group ( $\operatorname{tau}=0,308, p=0,066$ ). The Lean group presented more frequently a varus knee, while the knee alignment in the OA Obese group was in the normal range. Specifically, in the Obese group 8 knees were valgus, 2 varus and 2 normal, in the Lean group 7 knees were varus and 3 valgus.

Regarding the ultrasonographic characterisation of the quadriceps and patellar tendons, the Obese group presented a higher frequency of 1 and 2 scores, both for quadriceps enthesitis at the upper pole of the patella (tau=0.509; $p=0.001$ ) and for patellar enthesitis at the lower pole of the patella (chi squared $p=0.024$ ) (Tab. II). Tibial enthesitis was more frequent in the obese group ( $37 \%$ vs $20 \%$ of the Lean group; NS). Calcifications were present in 4 knees in the Obese group at the quadriceps enthesis, and in 2 knees at the tibial enthesis. No calcifications were found in the Lean group. Power Doppler evaluation did not show significant differences between the two groups.

The frequency of infrapatellar bursitis, synovitis and effusion of the supra-patella recess was not different between the groups (Tab. II).

Patellar and quadriceps peritendinopathy was detected in 1 only patient in each group. The course of the patellar tendon was within normality in the Lean group, while in 2 patients of the obese group (16.7\%) it was lateralised (chi squared $\mathrm{p}=0.034$ ). The muscle bulk of the rectus femoris was abnormal in $75 \%$ of patients of the Obese group compared to $40 \%$ of Lean group (tau=0.313; $p=0.073$ ) (Fig. 2). Muscular tissue fibroadiposus degeneration was more prevalent in the Obese group (54\%) compared to the Lean group (20\%) (NS).

\section{Discussion}

There is conflicting evidence regarding the possible association between obesity and pathological changes in the quadriceps and patellar tendons. Some studies report an association between the clinical diagnosis of patellar tendinopathy and increased BMI, but other studies in athletes suggest that weight is not a significant risk factor for patellar tendinopathy ${ }^{15}$.

However, in a study on community based adults without clinical evidence of knee pathology, MRI identified patellar tendon pathology in $28.3 \%$ of the subjects. The risk of MRI-defined patellar tendon pathology was associated with both current and past history of obesity ${ }^{15}$. Abnormalities in the composition and organization of extracellular matrix components of ten- 


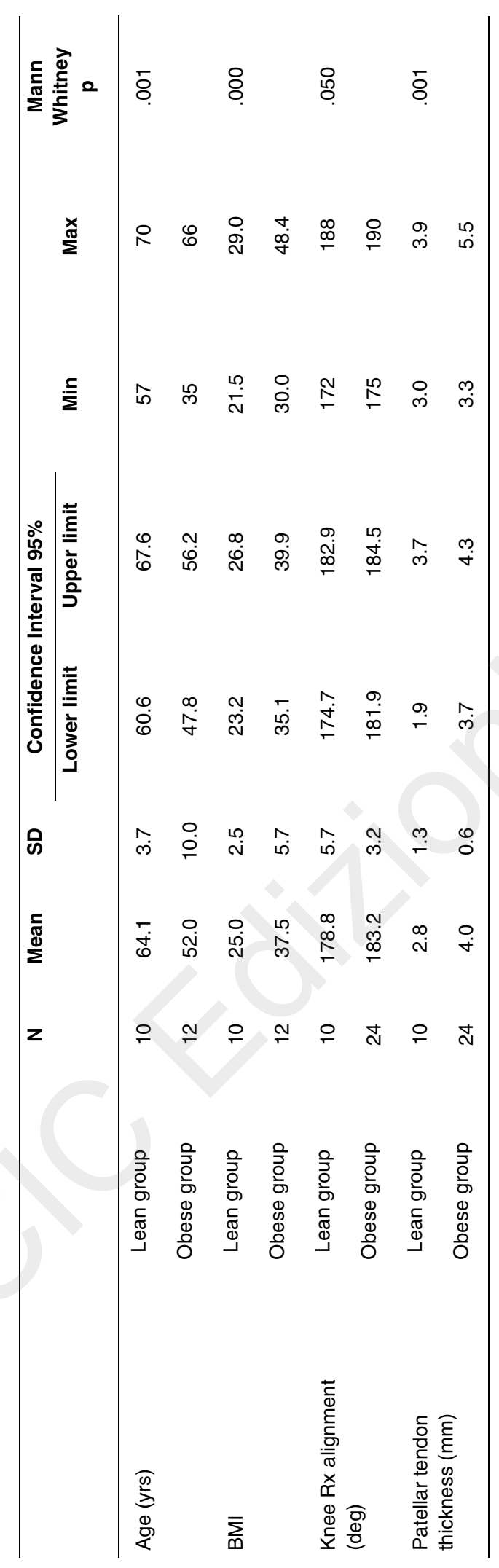

dons are present in obese Zucker rats ${ }^{24}$. These alterations might be related to organizational and structural modifications in the collagen bundles, influencing the mechanical properties of the tendon and progression towards clinically evident pathology.

Different ultrasonographic features, such as reduced thickness of the quadriceps tendon and suprapatellar effusion in symptomatic osteoarthritis knees, have also been associated with pain ${ }^{25,26}$. Meenagh et al. reported the presence of enthesopathy both at the upper and lower poles of patella and at the anterior tibial tuberosity in $85 \%$ of 61 painful knees in 35 patients. However, ultrasonography failed to highlight a relationship between soft tissue abnormalities and knee pain 27,28 .

Based on the relationship between knee OA and obesity, it is possible to speculate a common pathway in the onset and progression of knee OA in obese patients, both metabolically and mechanically mediated by the involvement of the extensor apparatus of the knee.

The present study confirmed the presence of patellar tendon abnormalities in the Obese group as well in the Lean group. Considering that the normal patellar tendon should nor exceed $7 \mathrm{~mm}^{29}$, the patellar tendon exhibited reduced thickness in OA knees. This is in agreement with previous work reporting a thinner patellar tendon (mean patellar thickness 2.75+0.19) in patients with symptomatic knee OA, and particurarly with higher $\mathrm{BMI}^{26}$. The presence of calcifications in the Obese group may also be the result of a chronic inflammatory process as a consequence of chronic repetitive tendon injury and quadriceps tendon overuse in obese subjects.

Quadriceps and patellar enthesitis was diagnosed in both groups at the superior pole (58\% obese vs $90 \%$ lean) and at the inferior pole (42\% obese vs $30 \%$ lean) of the patella, and at the anterior tibial tuberosity (37\% obese vs $2 \%$ lean). The presence of US sign indicative of entesopathy has been already described in knee OA patients ${ }^{28}$, and marked histopathological changes were found at the origin and insertion of the patellar tendon of cadavers, introducing the concept of "synovio-entheseal complex" to explain a possible link between enthesis involvement and inflammatory changes at or near attachment sites, probably reflecting high level of mechanical stress and "wear and tear" at entheses ${ }^{14}$.

Increased Power Doppler activity, indicating the presence of neovascularisation in abnormal patellar tendons, was rarely found in the present study (2 patients in the Lean group and 3 patients in the Obese group $^{28}$.

Effusion in the suprapatellar recess and synovitis were common in both groups (about $45 \%$ obese vs $60 \%$ lean), in agreement with previous reports in knee OA patients. Chan et al. ${ }^{30}$ reported the presence of suprapatellar recess effusion in $64.8 \%$ of the patients and synovitis in $37.8 \%$. De Miguel Mendieta et al. ${ }^{25}$ and Memerci et al. ${ }^{26}$ reported respectively suprapatellar effusion in $79 \%$ of the patients and syn- 
Table II. Ultrasonographic characterization of quadriceps and patellar tendons.

\begin{tabular}{|c|c|c|c|c|c|c|c|}
\hline & & \multicolumn{2}{|c|}{ Lean Group } & \multicolumn{2}{|c|}{ Obese Group } & \multirow[t]{2}{*}{ Chi Squared } & \multirow[t]{2}{*}{ Kendall Tau-b } \\
\hline & Score & $\mathrm{N}$ & $\%$ Patients & $\mathbf{N}$ & $\%$ Patients & & \\
\hline \multirow[t]{3}{*}{ Kellgren-Lawrence } & 1 & 2 & $20 \%$ & 13 & $54 \%$ & & \multirow{3}{*}{$\begin{array}{c}\operatorname{tau}=0.308 \\
p=0.066\end{array}$} \\
\hline & 2 & 5 & $50 \%$ & 8 & $33 \%$ & & \\
\hline & 3 & 3 & $30 \%$ & 3 & $13 \%$ & & \\
\hline \multirow{4}{*}{$\begin{array}{l}\text { Quadriceps enthesitis } \\
\text { superior pole }\end{array}$} & 0 & 1 & $10 \%$ & 10 & $42 \%$ & & \multirow{7}{*}{$\begin{array}{l}\text { tau }=0.509 \\
p=0.001\end{array}$} \\
\hline & 1 & 3 & $30 \%$ & 13 & $54 \%$ & & \\
\hline & 2 & 5 & $50 \%$ & 1 & $4 \%$ & & \\
\hline & 4 & 1 & $10 \%$ & 0 & $0 \%$ & & \\
\hline \multirow[t]{3}{*}{ Patellar enthesitis inferior pole } & 0 & 7 & $70 \%$ & 14 & $58 \%$ & \multirow[t]{6}{*}{$p=0.024$} & \\
\hline & 1 & 1 & $10 \%$ & 10 & $42 \%$ & & \\
\hline & 2 & 2 & $20 \%$ & 0 & $0 \%$ & & \\
\hline \multirow[t]{3}{*}{ Tibial enthesitis } & 0 & 8 & $80 \%$ & 15 & $63 \%$ & & \multirow[t]{5}{*}{ NS } \\
\hline & 1 & 2 & $20 \%$ & 8 & $33 \%$ & & \\
\hline & 2 & 0 & $0 \%$ & 1 & $4 \%$ & & \\
\hline \multirow[t]{2}{*}{ Power Doppler evaluation } & 0 & 8 & $80 \%$ & 21 & $88 \%$ & \multirow[t]{2}{*}{ NS } & \\
\hline & 1 & 2 & $20 \%$ & 3 & $13 \%$ & & \\
\hline \multirow[t]{2}{*}{ Bursitis of the infra-patellar bursa } & 0 & 5 & $50 \%$ & 18 & $75 \%$ & \multirow[t]{2}{*}{ NS } & \\
\hline & 1 & 5 & $50 \%$ & 6 & $25 \%$ & & \\
\hline \multirow{3}{*}{$\begin{array}{l}\text { Subquadricipital } \\
\text { receding synovitis }\end{array}$} & 0 & 4 & $40 \%$ & 13 & $54 \%$ & & \multirow[t]{3}{*}{ NS } \\
\hline & 1 & 6 & $60 \%$ & 6 & $25 \%$ & & \\
\hline & 2 & 0 & $0 \%$ & 5 & $21 \%$ & & \\
\hline \multirow{3}{*}{$\begin{array}{l}\text { Subquadricipital } \\
\text { withdrawal effusion }\end{array}$} & 0 & 4 & $40 \%$ & 14 & $58 \%$ & NS & \multirow[t]{9}{*}{ NS } \\
\hline & 1 & 3 & $30 \%$ & 9 & $38 \%$ & & \\
\hline & 2 & 3 & $30 \%$ & 1 & $4 \%$ & & \\
\hline \multirow[t]{2}{*}{ Patellar tendon course } & reg & 10 & $100 \%$ & 22 & $92 \%$ & \multirow[t]{2}{*}{$p=0.34$} & \\
\hline & lat & 0 & $0 \%$ & 2 & $8 \%$ & & \\
\hline \multirow{2}{*}{$\begin{array}{l}\text { Peritendinitis (patellar and } \\
\text { quadriceps) }\end{array}$} & 0 & 9 & $90 \%$ & 23 & $96 \%$ & \multirow[t]{2}{*}{ NS } & \\
\hline & 1 & 1 & $10 \%$ & 1 & $4 \%$ & & \\
\hline \multirow{2}{*}{$\begin{array}{l}\text { Muscular tissue fibroadipous } \\
\text { degeneration }\end{array}$} & 0 & 8 & $80 \%$ & 11 & $46 \%$ & \multirow[t]{2}{*}{ NS } & \\
\hline & 1 & 2 & $20 \%$ & 13 & $54 \%$ & & \\
\hline \multirow[t]{3}{*}{ Rectus femoris gradient } & 0 & 6 & $60 \%$ & 6 & $25 \%$ & & \multirow{3}{*}{$\begin{array}{l}\operatorname{tau}=0.313 \\
p=0.073\end{array}$} \\
\hline & 1 & 3 & $30 \%$ & 11 & $46 \%$ & & \\
\hline & 2 & 1 & $10 \%$ & 7 & $29 \%$ & & \\
\hline
\end{tabular}

ovitis in $72.3 \%$. However, they did not specify the BMI of the patients studied.

An ultrasonographic diagnosis of infrapatellar bursitis was more frequent compared to what reported by Bevers et al. ${ }^{27}(5.6 \%)$, and de Miguel Mendieta et al. ${ }^{25}$ $(8.6 \%)$, especially for lean patients with knee OA.

Abnormalities of peritenon at both tendons (patellar and quadriceps) were rare. Finally, the course of the patellar tendon was lateralized in 2 obese patients, probably from the increased bulk of the thigh tending to move laterally in the supine position during the ultrasonographic examination. In addition, obese patients often presented muscular tissue fibroadipous degeneration and a reduced rectus femoris gradient. Sarcopenia and intramuscular fat infiltration occur with aging ${ }^{10}$, but increased quadriceps intramuscular fat has been demonstrated in subjects with knee OA, and is related to symptomatic and structural severity of knee $O A^{9,10,20,31}$.

\section{Conclusion}

The present study provided evidence of quadriceps and patellar tendons abnormalities both in obese and lean patients with knee OA. Ultrasonography evi- 


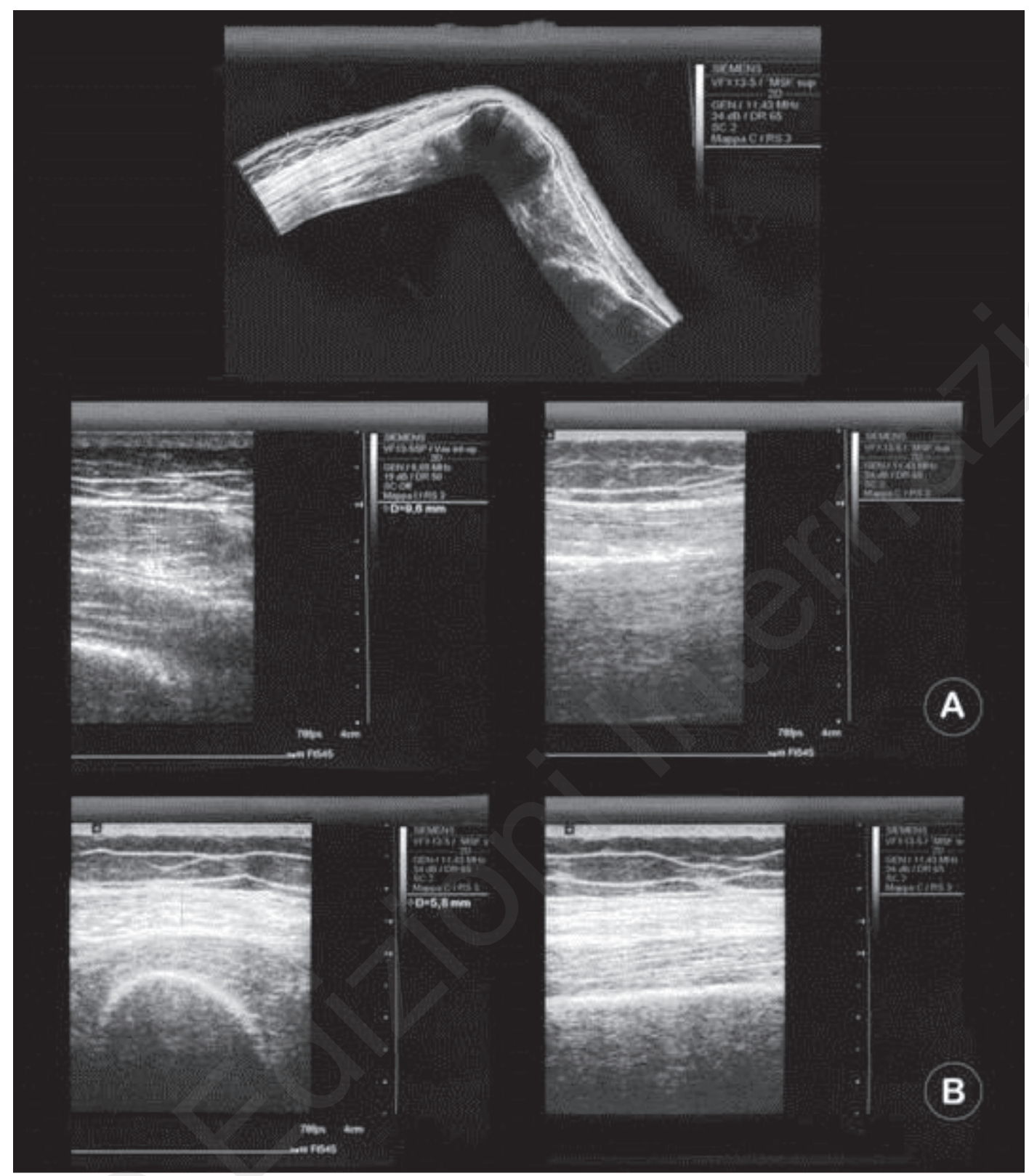

Figure 2. Upper image: panoramic ultrasound view of the extensor apparatus of the knee. A. Left: transverse ultrasound image of a normal rectus femoris muscle bulk ( $\mathrm{mm} \mathrm{9.6);} \mathrm{right:} \mathrm{longitudinal} \mathrm{ultrasound} \mathrm{image} \mathrm{of} \mathrm{a} \mathrm{normal} \mathrm{rectus} \mathrm{femoris} \mathrm{muscle}$ bulk; B. Left: transverse ultrasound image of a hypothophic rectus femoris muscle bulk (mm 5.8); right: longitudinal ultrasound image of a hypothophic rectus femoris muscle bulk.

denced the involvement of the peripatellar entheses, synovitis and effusion at the supra-patellar recess and muscular tissue fibroadipous degeneration, as well as loss of muscle mass in the rectus femoris. These were particularly evident in obese patients with knee OA. In accord with Fairley et al. ${ }^{15}$, a mechanical effect of obesity on patellar tendon pathology can be hypothesised, similar to what reported in patellar tendinopathy in athletes who experience repeated heavy loading through the patellar tendon. The pathogenetic role of systemic factors however cannot be excluded ${ }^{13,17}$.
In the present study, the obese patients group was significantly younger than the lean patients group and with a lower Kellgren-Lawrence degree of radiographic arthritis. The presence of quadriceps and patellar tendons abnormalities in obese patients with knee OA supports the hypothesis of a role of these structures in the early onset of knee pain.

The characteristics and the size of the Lean group was a limitation in the present study, as it is not representative of a population comparable for age and level of knee OA with the Obese group. However, it 
was extremely difficult to find younger lean patients with symptomatic primary knee OA. Another limitation was the lack of a radiographic assessment of the patello-femoral joint in obese knee OA patients to explore the presence of pathology in this compartment sustaining an anterior knee pain condition.

Nevertheless, this study demonstrated ultrasonographic abnormalities of quadriceps and patellar tendons in symptomatic knee OA obese patients.

\section{Competing interests}

The Authors declare that they have no competing interests. The study was carried out in the frame of the Ricerca Finalizzata 2005-2008 "Prevenzione delle complicanze dell'obesità: studio del metabolismo lipidico e patologia osteoarticolare", granted by the Italian Health Ministry N. G1890079.

\section{Authors' contributions}

BMG gave her contribute, conceiving and designing the study, interpreting the data and revising the article for relevant intellectual content. FA gave his contribute conceiving and designing the study and drafting the article, AD and GS performed the ultrasonographic evaluation, CL revised the literature, gathered and analyzed the data, BSS was responsible for the recruitment of the patients, CF and MN gave their contribute conceiving the study and revising the article for relevant intellectual content.

\section{Confict of interest}

The Authors declare that there are no conficts of interest.

\section{Compliance with ethical standards}

\section{Authors' information}

Not applicable.

\section{Acknowledgements}

The Authors are grateful to Elettra Pignotti, statistical engineer, for the statistical support.

\section{Ethics}

The Authors declare that this research was conducted following basic ethical aspects and international standards as required by the journal and recently update $i^{23}$.

\section{References}

1. Egloff $C$, Hügle $T$, Valderrabano V. Biomechanics and pathomechanisms of osteoarthritis. Swiss Med Wkly. 2012;142: w13583.

2. Herzog W, Longino D. The role of muscles in joint degeneration and osteoarthritis. J Biomech. 2007;40(Suppl 1):S54-63.

3. Teichtahl AJ, Wluka AE, Wang Y, Wijethilake PN, Strauss BJ, Proietto J, Dixon JB, Jones G, Forbes A, Cicuttini FM. (2015) Vastus medialis fat infiltration - a modifiable determinant of knee cartilage loss. Osteoarthritis Cartilage. 2015 Jul 8. pii: S1063-4584(15)01225-X

4. Harding GT, Hubley-Kozey CL, Dunbar MJ, Stanish WD, Astephen Wilson JL. Body mass index affects knee joint mechanics during gait differently with and without moderate knee osteoarthritis. Osteoarthritis Cart. 2012;20(11):1234-1242.

5. Raynauld JP, Pelletier JP, Roubille C, Dorais M, Abram F, Li W, Wang Y, Fairley J, Cicuttini FM, Martel-Pelletier J. (2015) Vastus medialis muscle fat content as assessed by mri is a risk factor for knee osteoarthritis progression: Relevance from a clinical trial. Arthritis Care Res (Hoboken).

6. Syed IY, Davis BL. Obesity and osteoarthritis of the knee: hypotheses concerning the relationship between ground reaction forces and quadriceps fatigue in long-duration walking. Med Hypotheses. 2000;54(2):182-185.

7. Bliddal $\mathrm{H}, \mathrm{Christensen} \mathrm{R}$. The management of osteoarthritis in the obese patient: practical considerations and guidelines for therapy. Obes Rev. 2006;7(4):323-331.

8. Bennell KL, Wrigley TV, Hunt MA, Lim BW, Hinman RS. Update on the role of muscle in the genesis and management of knee osteoarthritis. Rheum Dis Clin North Am. 2013;39(1): 145-176.

9. Kumar D, Karampinos DC, MacLeod TD, Lin W, Nardo L, Li X Link TM, Majumdar S, Souza RB. Quadriceps intramuscular fat fraction rather than muscle size is associated with knee osteoarthritis. Osteoarthritis Cart. 2014;22(2):226-234.

10. Tomlinson DJ, Erskine RM, Winwood K, Morse Cl, Onambélé GL. The impact of obesity on skeletal muscle architecture in untrained young vs. old women. J Anat. 2014;225(6):675-684.

11. Wakefield RJ, Balint $P$, Szkudlarek M, Filippucci E, Backhaus $M$, Scheel AK, et al. OMERACT 7 Special Interest Group. Musculoskeletal ultrasound including definitions for ultrasonographic pathology. J Rheumatol. 2005;32:2485-2487.

12. Kluzek S, Newton JL, Arden NK. Is osteoarthritis a metabolic disorder? Br Med Bull. 2015. pii: Idv028

13. Abate M, Oliva F, Schiavone C, Salini V. Achilles tendinopathy in amateur runners: role of adiposity (Tendinopathies and obesity). Muscles Ligaments Tendons J. 20122(1):44-48.

14. Benjamin M, McGonagle D. Histopathologic changes at "synovio-entheseal complexes" suggesting a novel mechanism for synovitis in osteoarthritis and spondylarthritis. Arthritis Rheum. 2007;56(11):3601-3609.

15. Fairley J, Toppi J, Cicuttini FM, Wluka AE, Giles GG, Cook J, O'Sullivan R, Wang Y. Association between obesity and magnetic resonance imaging defined patellar tendinopathy in community-based adults: a cross-sectional study. BMC Musculoskelet Disord. 2014;15:266.

16. Franceschi F, Papalia R, Paciotti M, Franceschetti E, Di Martino A, Maffulli N, Denaro V. Obesity as a risk factor for tendinopathy: a systematic review. Int J Endocrinol. 2014; 670262.

17. Frizziero A, Vittadini F, Gasparre G, Masiero S. Impact of oestrogen deficiency and aging on tendon: concise review. Muscles Ligaments Tendons J. 2014:4(3):324-328.

18. Kelly BM, Rao N, Louis SS, Kostes BT, Smith RM. Bilateral, simultaneous, spontaneous rupture of quadriceps tendons without trauma in an obese patient: a case report. Arch Phys Med Rehabil. 2001;82(3):415-418. 
19. Johns Hopkins Arthritis Centre. ACR clinical classification criteria for OA of Knee. http://www.Hopkins-arthritis.org/physiciancorner/education/acr/acr.Html\#class_knee.

20. Segal NA, Zimmerman MB, Brubaker M, Torner JC. Obesity and knee osteoarthritis are not associated with impaired quadriceps specific strength in adults. PM R. 2011;3(4):314323.

21. Beggs I, Bianchi S, Bueno A, Cohen M, Court-Payen M, Grainger A, et al. (2012) Musculoskeletal ultrasound technical guidelines: V. Knee. European Society of Musculoskeletal Radiology Accessed 05-01-2012 on. http://www.essr.org/ $\mathrm{html} / \mathrm{img} / \mathrm{pool} / \mathrm{knee} . \mathrm{pdf}$.

22. Lindehammar $\mathrm{H} 1$, Sandstedt $P$. Measurement of quadriceps muscle strength and bulk in juvenile chronic arthritis. A prospective, longitudinal, 2 year survey. J Rheumatol. 1998;25(11):2240-2248.

23. Padulo J, Oliva F, Frizziero A, Maffulli N. Muscles, Ligaments and Tendons Journal - Basic principles and recommendations in clinical and field science research: 2016 update. MLTJ 2016;6(1):1-5.

24. Biancalana A, Velloso LA, Taboga SR, Gomes L. Implications of obesity for tendon structure, ultrastructure and biochemistry: a study on Zucker rats. Micron. 2012;43(2-3):463-469.

25. de Miguel Mendieta E, Cobo lbáñez T, Usón Jaeger J, Bonilla Hernán G, Martín Mola M. Clinical and ultrasonographic findings related to knee pain in osteoarthritis. Osteoarthritis Cart
2006;14(6):540-544.

26. Mermerci BB, Garip Y, Uysal RS, Doğruel H, Karabulut E, Ozoran $\mathrm{K}$, Bodur $\mathrm{H}$. Clinic and ultrasound findings related to pain in patients with knee osteoarthritis. Clin Rheumatol. 2011;30(8):1055-1062.

27. Bevers K, Bijlsma JW, Vriezekolk JE, van den Ende $\mathrm{CH}$, den Broeder AA. Ultrasonographic features in symptomatic osteoarthritis of the knee and relation with pain. Rheumatology (Oxford). 2014;53(9):1625-1629.

28. Meenagh G, Filippucci E, Delle Sedie A, lagnocco A, Scirè CA, Riente L, Montecucco C, Valesini G, Bombardieri S, Grassi W. (2010) Ultrasound imaging for the rheumatologist XXX. Sonographic assessment of the painful knee. Clin Exp Rheumatol. 28(6):803-805

29. Pfirrmann CW, Jost B, Pirkl C, Aitzetmüller G, Lajtai G Quadriceps tendinosis and patellar tendinosis in professional beach volleyball players: sonographic findings in correlation with clinical symptoms. Eur Radiol. 2008;18(8):1703-1709.

30. Chan KK, Sit RW, Wu RW, Ngai AH. Clinical, radiological and ultrasonographic findings related to knee pain in osteoarthritis. PLoS One. 2014;9(3):e92901.

31. Runhaar J, van Middelkoop M, Reijman M, Vroegindeweij $D$, Oei EH, Bierma-Zeinstra SM. Malalignment: a possible target for prevention of incident knee osteoarthritis in overweight and obese women. Rheumatology (Oxford). 2014;53(9):16181624. 